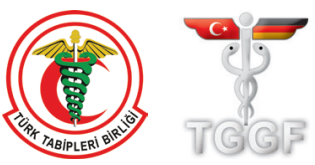

\title{
Premenstrual syndrome, a common but underrated entity: review of the clinical literature
}

\author{
(D) Berna Dilbaz, (D) Alperen Aksan \\ Department of Obstetrics and Gynecology, University of Health Sciences Turkey, Etlik Zübeyde Hanım Women's Health and \\ Research Center, Ankara, Turkey
}

\begin{abstract}
Premenstrual syndrome (PMS) and premenstrual dysphoric disorder (PMDD) are characterized by somatic and psychologic symptoms that arise at the luteal phase of the menstrual cycle and subside with menstruation. For definitive diagnosis prospectively self-reported symptoms should demonstrate a cyclic pattern and other psychological pathologies and thyroid dysfunction, that may present with similar symptoms, should be excluded. Both entities affect millions of women at reproductive age as the prevalence of PMS is given as 10-98\% while PMDD affects 2-8\%. Sex steroids and neurotransmitters have a central role in the etiology. The role of vitamins and minerals in the etiology and treatment of PMS and PMDD is open to discussion. Drugs that suppress ovarian sex steroid production, such as combined oral contraceptives or selective serotonin reuptake inhibitors enhancing central serotonin delivery are used for treatment. Life-style changes and regular exercise also have a positive effect in milder cases. Tricyclic antidepressants and gonadotropin-releasing hormone analogues can be used in selected cases. (J Turk Ger Gynecol Assoc 2021; 22: 139-48)
\end{abstract}

Keywords: Premenstrual syndrome, premenstrual dysphoric disorder, etiology, treatment

Received: 28 July, 2020 Accepted: 06 January, 2021

\section{Introduction}

Premenstrual syndrome (PMS) is an entity characterized by the presence of psychiatric symptoms such as mood swings, depression, loss of confidence, anxiety and irritability, without any underlying psychiatric disorder, accompanied by physical symptoms. Typical complaints include bloatedness and mastalgia encountered at the luteal phase of the menstrual cycle (LPMC), that deteriorates the well-being of the women and then subsides or disappears with menstruation (1). PMS affects a huge proportion of women at reproductive age and is characterized by the cyclic recurrence of a range of symptoms shown in Table 1 during the LPMC (2-4). Symptoms occur mostly in women of 25-35 years old, although it may be observed at any age between adolescence and menopause. Premenstrual dysphoric disorder (PMDD) is at the more severe end of the PMS spectrum that is characterized by the cyclic recurrence of psychological manifestations including irritability, nervousness, agitation, anger, insomnia, difficulty in concentrating, severe fatigue, depression, anxiety, and confusion. In addition, neurologic and vascular conditions are present which may include headache, dizziness, numbness, heightened sensitivity of arms and/or legs, palpitations, gastrointestinal and ocular symptoms that disrupt the daily life and functioning of the affected women. The mood disorder symptoms that are experienced both in PMS and PMDD disappear within the first days of menstruation. The Diagnostic and Statistical Manual of Mental Disorders-5 (DSM-5) established seven criteria (A through G) for the diagnosis of PMDD and at least five of these symptoms should be present, and should include one of the first four (A-D) (5). Both PMS and PMDD show a cyclic pattern with affective, behavioral and somatic symptoms beginning at the LPMC and disappearing within a few days after the onset of menstruation. These cyclic symptoms can also be observed in amenorrheic, reproductive aged women who had a hysterectomy but have functioning ovaries. 


\section{Epidemiology and prevalence}

During the LPMC at least one physical or psychiatric symptom is observed in $80 \%$ of the women. However most of them do not report any change in their daily life and activities (6). In a study of 2800 French women $12 \%$ demonstrated the diagnostic symptoms of PMS while only $4 \%$ had more severe symptoms (7). Although most women experience one or a few of these symptoms during the LPMC, only 3-8\% demonstrate clinically significant PMS symptoms (8).

Three prospective, population-based studies that utilized the strict criteria for diagnosis of PMDD reported a prevalence of approximately $2 \%$ among the study population $(8,9)$.

In a study conducted at Switzerland in 2007, a total of 3,913 women aged 15 to 54 responded to a questionnaire inquiring about PMS symptoms and 3,522 (90\%) reported that PMS affected their daily life. While $90 \%$ had at least one symptom, $10.3 \%$ had PMS, and 3.1\% met the PMDD criteria (10).

Also, in a meta-analysis covering 18,803 women, the overall prevalence of PMS was 47.8\% [95\% confidence interval (CI): 32.6-62.9]. The lowest and highest prevalence were reported as 12\% (95\% CI: 11-13) in France and 98\% (95\% CI: 97-100) in Iran, respectively. The authors emphasized that the prevalence of PMS was studied more in Asia than in other continents (11). A global study involving 7,226 women from South America, Europe and Asia, investigating the frequency of PMS symptoms and found the frequency to be parallel between countries and the regions, but in some countries, such as Pakistan, women were found to be less familiar with the term PMS compared to European women (12).

\section{Risk factors for PMS and PMDD}

The role of genetic factors in the predisposition to PMS and PMDD has been an active and interesting area for many researchers yet definitive conclusions have not emerged. Some studies suggest a possible association with estrogen receptor alpha (ESR1) gene (13-15). In one report, cells from women with and without PMDD appeared to show different response patterns to the components of the ESC/E (Z) complex containing the ESR1 gene (16). Other risk factors for PMDD development include lower levels of education and smoking (17), history of traumatic events or anxiety disorder, and higher daily difficulty scores (18).

\section{Etiology and pathogenesis}

Although various hypotheses have been put forward, the etiology of PMS and PMDD is not fully understood (19). The best-known hypothesis is the presumed role of circulating gonadal steroids in the development of PMS symptoms, as suppression of ovulation has a beneficial effect on PMS (20-22). However, cyclic changes in ovarian steroids do not appear to be the only cause of PMS symptoms, as daily serum progesterone and estrogen concentrations are shown to be similar in women with and without PMS. An early study by Andersch et al. (23) demonstrated that, apart from prolactin levels, which were lower in the follicular phase of the PMS group, all the sex steroids were present in similar concentrations in both the control and the PMS groups in the LPMC. In two studies no correlation was found between serum progesterone levels and the affective and/or somatic symptoms $(24,25)$. Deficiencies in progesterone, progesterone metabolites (some of which have anxiolytic effects) and progesterone receptor function have also been proposed to be a possible cause of PMS/PMDD. However, as mentioned, serum progesterone concentrations are normal in women who have PMS. In addition, serum concentrations of the progesterone metabolites allopregnanolone and pregnenolone are similar in women with PMS and without PMS (25). It has been shown that blocking the effect of progesterone in the LPMC with a progesterone receptor antagonist, such as mifepristone, does not alleviate PMS symptoms (26). Women with PMS may have an abnormal response to normal ovarian hormonal changes, even though serum progesterone and estrogen concentrations are within normal limits (21).

Current evidence suggests that PMS is a disorder triggered by changes in gonadal steroids during the LPMC in susceptible women. This is thought to be due to the interaction between cyclic changes in ovarian steroids and the functioning of central neurotransmitters. One of the most frequently investigated neurotransmitters in PMS pathogenesis is serotonin, but beta-endorphine, gamma-aminobutyric acid (GABA) and the autonomic nervous system are also part of the pathogenesis of PMS. Based on in vitro data and animal studies, there is evidence that cyclic variation in circulating estrogen and progesterone result in marked changes in the opioid (27), GABA (28) and serotonin (29) systems.

The potential role of the GABAergic system in PMS has not been extensively investigated previously. The main effect of GABA is to reduce cellular excitability through a chloride system. The hypothesis that suggests a modulatory role of progesterone in the GABAergic system is supported by the improvement observed in PMS symptoms when agents such as benzodiazepine and alprazolam, that increase GABAergic activity, are used (30). Additionally, GABA-A enhances receptor function and has anxiolytic effects. Low levels of the progesterone metabolite allopregnanolone are shown to produce a similar anxiolytic effect (31).

Current studies highlight the pivotal role of serotonin in the etiology of PMS. In a number of studies, patients with PMS have been shown to have lower levels of whole blood 
serotonin, platelet serotonin, and imipramine binding and serotonin metabolites in the LPMC (32-36). In cerebrospinal fluid, 5-hydroxyindoleacetic acid has been shown to be present in higher levels compared to the dopamine metabolite homovanillic acid (37). In a study by Brzezinski et al. (38) and Menkes et al. (39), improvement in PMS symptoms was achieved with the serotonin agonist fenfluramine (38) and aggravated with acute reduction of the serotonin precursor tryptophan (39). In addition, selective serotonin reuptake inhibitors (SSRI) that increase the serotonin level in brain, such as fluoxetine, are one of the most effective drugs for treatment of PMS.

The role of minerals and vitamins in the etiology of PMS is still controversial. In previous studies, vitamin E, vitamin A or vitamin B6 levels were not different in women who have PMS $(40,41)$. Several vitamins and dietary supplements have been studied as therapeutic agents for PMS, including vitamin E, B, vitex agnus castus, calcium, zinc, and magnesium. However, the evidence showing any of these are more effective than placebo is scarce. A Cochrane review that described a protocol for vitex agnus castus use for PMS was withdrawn (Cochrane Database of Systematic Reviews 2018, issue 3. art. no.: CD004632.). Also, although several studies related to iron, magnesium, zinc, zinc to potassium ratio, and calcium are present in the literature, their role in the treatment and etiology of PMS/PMDD is still debatable $(41,42)$.

\section{Diagnostic criteria for PMS and PMDD}

Many groups have published diagnostic criteria for premenstrual diseases, including the World Health Organization, American College of Obstetricians and Gynecologists (ACOG), Royal College of Obstetricians and Gynecologists (RCOG), International Society for Premenstrual Disorders (ISPMD) and the American Psychiatric Association (APA; DSM-5) (1). ACOG describes symptoms consistent with PMS as: 1- The symptoms should be restricted to the LPMC; 2- The symptom pattern should be confirmed by prospective evaluation; 3- symptoms should cause functional impairment; and 4- other diagnoses that could better explain the symptoms should be excluded (43). The ACOG definition involves the presence of at least one of the six affective symptoms (angry outbursts, depression, anxiety, confusion, irritability and social withdrawal) and one of the four somatic symptoms (abdominal bloating, headache, breast tenderness, and swelling of extremities) reported five days prior to the onset of menses in the three prior menstrual cycles which have ceased within 4 days of onset of menses (43). ACOG has added more symptoms in the patientavailable resources which include emotional symptoms such as depression, irritability, angry outbursts, crying spells, social withdrawal, anxiety, confusion, poor concentration, insomnia, increased nap taking, and changes in sexual desire, while physical symptoms include thirst and appetite changes (food cravings), weight gain, breast tenderness, bloating and headache, swelling of the hands or feet, aches and pains, abdominal pain, fatigue, skin problems, and gastrointestinal symptoms (https://www.acog.org/patient-resources/faqs August 2020).

The RCOG recommends keeping a self-reported symptom diary by the women for recording the symptoms for diagnosis of PMS and that the symptoms should be observed prospectively over two cycles (44).

ISPMD published a consensus article on the management of PMD and cited the classification published by O'Brien et al. (45) in 2011. According to this classification (46) two entities are described which are: 1) Core premenstrual disorder (CPD); and 2) Variant premenstrual disorders. The symptom characteristics of CPD can be somatic and/or psychological and were stated as occurring in ovulatory cycles, being absent after menstruation, and before ovulation, recurring in the luteal phase and be prospectively rated for at least two cycles. In addition, CPD symptoms should cause significant impairment of daily life (work, school, social activities, hobbies, interpersonal relationships, and distress). PMDD was defined as a sub-group of CPD. The variants of PMD were: a) Menstrual exacerbation of symptoms of an underlying somatic, psychological or medical disorder that significantly worsens premenstrually; b) PMD due to non-ovulatory ovarian activity; c) Progestogen-induced PMD related to exogenous progestogen administration; and d) PMD with absence of menstruation due to ongoing ovarian activity.

PMS is currently being diagnosed when any one of the four symptoms that may be physical, behavioral, or emotional/ psychological (with at least one being emotional) or physical or behavioral and five or more symptoms are present. However, if a woman has five or more symptoms and one of them is an "emotional symptom", it would be better to diagnose PMDD instead of PMS (Table 1).

PMDD, classified by the APA, should include five of the 11 symptoms required to meet the diagnostic criteria, defined in DSM-5 and at least one of these should involve mood swings (5). Currently the APA DSM-5 system, that defines PMDD criteria, is used for diagnosis. These criteria specify that: a) prospective documentation of behavioral and physical symptoms (using diaries) for most of the previous year should be available; b) accompanied by five or more symptoms that occur in the week before the onset of menstruation and disappear within a few days of the onset of menstruation. These criteria also indicate that PMDD can overlap with other psychiatric disorders but in these patients the symptoms do not exacerbate in the luteal phase. 
According to the DSM-5 criteria, one or more of the following must be present for the diagnosis of PMDD: a) anger/irritability b) sudden sadness, increased sensitivity, mood swings to rejection; c) tension and anxiety; and d) depressed mood, feeling hopeless, self-critical thoughts.

To achieve a total of five symptoms, one or more of the following symptoms must also be present:

a. Premenstrual irritability,

b. Concentration difficulty,

c. Appetite change, overeating, food cravings,

d. Decreased interest in ordinary activities,

e. Easily fatigued, having reduced energy,

f. Feeling overwhelmed or out of control,

g. Bloating, breast tenderness, weight gain, or joint/muscle pain, h. Sleeping too much or not getting enough sleep.

These symptoms should occur in the luteal phase and must be severe enough to deteriorate daily functions (work, school, social life).

Table 1. Most frequent symptoms of premenstrual syndrome (2-4)

\begin{tabular}{|c|c|}
\hline \multicolumn{2}{|c|}{ Most frequent dymptoms of PMS } \\
\hline \multirow{5}{*}{ Behavioral symptoms } & Fatigue \\
\hline & Insomnia or needing more sleep \\
\hline & Dizziness \\
\hline & Sexual dysfunction \\
\hline & Overeating \\
\hline \multirow{13}{*}{ Psychologic symptoms } & Nervousness \\
\hline & Anger \\
\hline & Depressive mood changes \\
\hline & Anxiety \\
\hline & Mood changes \\
\hline & Difficulty in concentrating \\
\hline & Confusion \\
\hline & Forgetfulness \\
\hline & Emotional sensitivity \\
\hline & Poor self-esteem \\
\hline & Emotional insensitivity \\
\hline & Agitation \\
\hline & Restlessness \\
\hline \multirow{7}{*}{ Physical symptoms } & Headache \\
\hline & Mastodynia and mastalgia \\
\hline & Backache and/or abdominal pain \\
\hline & Bloating, weight gain \\
\hline & Swollen ankles, hands and feet \\
\hline & Nausea \\
\hline & Muscle and joint pain \\
\hline
\end{tabular}

\section{Symptoms}

Women with PMS experience a wide range of cyclic and recurrent emotional, physical, behavioral and cognitive symptoms that begin in the LPMC and resolve shortly after the onset of the menstrual period (follicular phase). The number of symptoms seen in the majority of patients is much more limited (47). However, core symptoms include emotional symptoms such as depression, irritability and anxiety, and somatic symptoms such as breast pain, bloating and swelling and headache (Table 1). For most women, the types of symptoms are consistent between periods and usually last an average of six days a month (48). Besides affective symptoms, women with PMDD, also have physical symptoms. Analysis of prospective symptom studies in women with PMDD shows that mood and physical symptoms are usually the most severe (and with functional impairment) within four days before menstruation in the first two to three days (49).

The most common emotional or behavioral symptom in PMS is mood swings. Other non-physical behavioral symptoms include irritability, anxiety/tension, sadness or depressed mood, increased appetite, sensitivity to rejection, and decreased interest in activities (47). The most common physical symptoms in PMS are abdominal bloating and excessive fatigue followed by breast tenderness, headache, dizziness and flushing (47). Hot flushes, similar to menopausal hot flushes, that occur before menstruation suggest PMS or PMDD in women who are not in postpartum or menopause (50).

Many symptoms associated with PMS significantly affect quality of life, ranging from a moderate to a severe effect and PMS symptoms have been associated with decreased health-related quality of life $(51,52)$.

\section{Differential diagnosis}

For differential diagnosis of PMS and PMDD the entities given in Table 2 should be ruled out (Table 2) $(43,44,46)$.

\section{Physical examination}

There is no specific finding on physical examination in women with PMS/PMDD. Physical examination might be useful in ruling out other entities, such as endometriosis.

\section{Laboratory findings}

There is no specific biochemical or any other tests to diagnose PMS. Daily gonadotropin and sex steroid serum concentrations are not different from women with and without PMS $(23,24)$. Thyroid tests might be useful in order to exclude hypothyroidism. 


\section{General approach and treatment}

A thorough evaluation of patients with PMS or PMDD is required (Table 3). The cyclic occurence of symptoms should be confirmed by careful questioning. It might be difficult to interpret in women who have PMS or PMDD with irregular menses. The etiology of the irregular menses should be investigated. In women who are using combined oral contraceptives the timing of the initiation of the symptoms and the relation to the onset or termination of the combined pill should be queried. Various screening tools or applications can be used for self-reporting the symptoms. In cases where the self-reported dairy is not conclusive, the RCOG recommends the use of GnRH testing. PMS can be diagnosed if the symptoms subside when ovarian hormonal suppression is obtained with $\mathrm{GnRH}$ analogues.

\section{Treatment}

The main goal of treatment for women with PMS/PMDD is to alleviate and improve symptoms and enable normal daily life. Various approaches, ranging from lifestyle measures (exercise and relaxation techniques), to cognitive behavioral therapy

Table 2. Differential diagnosis of premenstrual syndrome and premenstrual disphoric disorder

\begin{tabular}{|l|}
\hline Affective disorder (depression, anxiety, dysthymia, panic) \\
\hline Anemia \\
\hline Anorexia or bulimia \\
\hline $\begin{array}{l}\text { Chronic medical conditions (diabetes mellitus, hyperthyroidism, } \\
\text { hypothyroidism) }\end{array}$ \\
\hline Dysmenorrhea \\
\hline Endometriosis \\
\hline Hypothyroidism \\
\hline Oral contraceptive pill or progestin-only contraceptive use \\
\hline Perimenopause \\
\hline Personality disorder \\
\hline Substance abuse disorders \\
\hline
\end{tabular}

Table 3. Steps for evaluation of patients with PMS and PMDD

Take a detailed history of the symptoms and their relationship with the phase of the menstrual cycle

Take a medical history, including hormonal therapy and contraceptive drug use

Endocrine disorders should be evaluated and investigated (thyroid stimulating hormone)

If the symptoms are consistent with PMS/PMDD and other medical conditions are excluded, the patient should be asked to prospectively record symptoms for two months in order to confirm the diagnosis

PMS: Premenstrual syndrome, PMDD: Premenstrual dysphoric disorder
(CBT) and medications (SSRIs), and/or combined estrogenprogestin contraceptives (COC), are utilized for treatment of PMS and PMDD.

\section{Treatment of mild symptoms}

Regular exercise and stress reduction techniques are efficient and cost-effective treatment options in women with mild premenstrual symptoms. Exercise is particularly useful for physical symptoms (53).

Vitex agnus castus is a popular herbal remedy that is used as a dry extract, tincture or liquid for treatment of PMS symptoms. The mode of action and pharmacodynamics is not yet completely understood. In animal studies it is shown to act on the dopaminergic receptors leading to a reduction of prolactin secretion. Van Die et al. (54) reported vitex agnus castus to be more effective than placebo for PMS symptoms, while its effectiveness for PMDD is less prominent.

Although a range of vitamins and dietary supplements, including St. John's Wort, evening primrose oil, vitamin B6, vitamin $\mathrm{E}$, vitamin $\mathrm{D}$, zinc, calcium, iron and magnesium, have been studied as therapeutic agents for mild PMS, the evidence that demonstrates an increased effectiveness of these agents when compared to placebo is not sufficient $(41,42,44,55)$.

\section{Treatment of moderate and severe symptoms}

A holistic approach conducted by a team consisting of gynecologist, clinical psychologist, psychiatrist or counsellor, and a dietician is required in treating women with moderate to severe PMS and PMDD (44). The best approach for women who meet the criteria of PMS or PMDD, is to have pharmacological and/or behavioral intervention, such as CBT. CBT aims to help people to identify and change destructive or disturbing negative thought patterns. However, before starting treatment, other conditions with symptoms that may overlap with PMS/ PMDD, should be ruled out.

There are two targets for first-line pharmacotherapy of moderate to severe PMDD:

a. Enhancing central serotonergic delivery. Serotonin augmenting drugs alleviate PMDD symptoms, therefore SSRIs are highly effective in treatment of PMDD,

b. Suppressing the hypothalamic-pituitary-ovarian axis to eliminate physiologic cyclic changes of ovarian sex-steroids by either GnRH agonists or COCs.

SSRIs should be preferred in women who do not desire to use contraceptive pills. However, if the patient needs contraception, combined oral contraceptives should either be the first- choice or combined with SSRIs therapy.

SSRIs are reported to be effective in clinical trials and systematic reviews $(44,56)$. A Cochrane review compared the 
effectiveness of paroxetine, fluoxetine, escitalopram, sertraline and citalopram with placebo and concluded that SSRIs reduced overall self-rated symptoms significantly more effectively than placebo when either used continuously or during the LPMC (57). Paroxetine is also effective, but is associated with weight gain (58). The beneficial effect of SSRIs will occur as early as the first cycle. If the response is low, the dose may be increased before the next cycle. Although the Cochrane review demonstrated SSRI's therapeutic effect on both somatic and psychological symptoms, they appear to be more effective for mood symptoms than somatic symptoms (46).

The serotonin-norepinephrine reuptake inhibitor (SNRI), Venlafaxine, has also been reported to be more effective for PMDD than placebo, but SSRIs are still advised as firstline therapy because venlafaxine causes more withdrawal symptoms than SSRIs $(59,60)$.

Tricyclic antidepressants can also be used. Clomipramine (given during the menstrual cycle or limited to the LPMC) is more effective than placebo, but its routine use is not recommended due to its side effects (sedation, dry mouth, and weight gain) $(61,62)$.

Three protocols used for treatment of moderate to severe symptoms of PMS and PMDD by SSRIs are: continuous daily administration, luteal phase therapy, or symptom initiated therapy. The choice of regimen depends on the duration and timing of the symptoms (including their predictability) and the patient's preference.

1. Continuous use: SSRIs are effective for premenstrual symptoms, whether taken continuously or intermittently (63). Continuous administration is recommended for women with mild symptoms occurring with long-term intervals, as the onset of symptoms cannot be predicted. In woman with serious physical symptoms, continuous dose regimens are more effective than intermittent regimens (60).
2. Luteal phase protocols: This is recommended for women with predictable symptoms that last more than a week before the onset of menstruation (64). The treatment is commenced on the $14^{\text {th }}$ day of the cycle and usually stopped at the beginning of menstruation, but it can continue for a few more days in women with a persistent history of symptoms. This regimen is less expensive and causes fewer side effects. Some individual studies $(65,66)$ and the Cochrane review (46) have reported that SSRIs are equally effective in symptom relief when taken continuously or only in the luteal phase. It has also been reported in some studies that higher doses of SSRI are required in some women receiving luteal phase therapy to adequately treat physical symptoms $(65,66)$.

3. Symptom onset treatment: Intermittent therapy has been shown to be effective from the onset of symptoms to the first days of the month (67). In a randomized study by Yonkers et al. (48), symptom onset therapy with SSRIs was more effective than placebo. Symptom onset therapy is recommended for women with symptoms for a week or less who can easily recognize the onset of their own symptoms $(68,69)$. If intermittent treatments are ineffective or difficult for patients, continuous treatment is recommended (69).

The doses used for PMDD are similar to those used to treat depression. Recommended SSRI doses for SSRI regimens are given in Table 4.

Although the majority of symptomatic women respond to an SSRI, around $30 \%$ to $40 \%$ may not show any improvement (64). The dose of the SSRI should be adjusted according to the symptoms and lack of response to treatment should not be diagnosed after observing several treatment cycles (64). The possible adverse effects of SSRIs are insomnia, nausea, somnolence, fatigue and reduction in libido (44). Changing the SSRI initiated to a newer agent or switching to luteal phase therapy should be considered in women with side-effects

Table 4. Recommended SSRI doses for premenstrual dysphoric disorder (64)

\begin{tabular}{|l|l|l|l|}
\hline SSRI & Starting dose (per day) & Usual effective doses* (per day) & Maximum dosage**(per day) \\
\hline Citalopram & $10 \mathrm{mg}$ & $20-30 \mathrm{mg}$ & $\begin{array}{l}\text { Continous } 40 \mathrm{mg} \\
\text { Intermittent } 30 \mathrm{mg}\end{array}$ \\
\hline Escitalopram & $5-10 \mathrm{mg}$ & $10-20 \mathrm{mg}$ & $\begin{array}{l}\text { Continous } 20 \mathrm{mg} \\
\text { Intermittent } 20 \mathrm{mg}\end{array}$ \\
\hline Fluxetine & $10 \mathrm{mg}$ & $20 \mathrm{mg}$ & $\begin{array}{l}\text { Continous } 30 \mathrm{mg} \\
\text { Luteal phase } 30 \mathrm{mg} \\
\text { Symptom onset } 20 \mathrm{mg}\end{array}$ \\
\hline Paroxetine & $10 \mathrm{mg}$ & $20-30 \mathrm{mg}$ & $\begin{array}{l}\text { Continous } 40 \mathrm{mg} \\
\text { Intermittent } 30 \mathrm{mg}\end{array}$ \\
\hline Sertraline & $25 \mathrm{mg}$ & $50-150 \mathrm{mg}$ & $\begin{array}{l}\text { Continous } 200 \mathrm{mg} \\
\text { Intermittent } 150 \mathrm{mg}\end{array}$ \\
\hline
\end{tabular}

*The starting dose can be increased to the usual effective dose if the initial dose is not sufficient to suppress the symptoms, ${ }^{* *}$ Maximum dosage required if symptom control is not achieved with the usual effective dose after a number of treatment cycles.

SSRI: Selective serotonin reuptake inhibitors 
(69). If the patient fails to show any improvement with more than one SSRI agents, other diseases mimicking PMS/PMDD symptoms, such as PCOS [in which there is a 3.39 times increased risk for depression and a 3.64 times increased risk for anxiety (70)], major depression or substance use disorder must be investigated. In order to avoid withdrawal symptoms, SSRIs if used continuously, should be discontinued gradually. The patients should not continue taking SSRIs prior to and during pregnancy. The optimal duration of the treatment with SSRIs is unknown. The treatment can be continued until women with recurrent symptoms become pregnant or reach menopause (44).

\section{Treatment with combined oral contraceptives}

For women with moderate to severe symptoms seeking hormonal contraception, treatment with a COC is recommended, as these medications suppress the hypothalamic-pituitary-ovarian axis and ovulation. Monophasic preparations should be preferred as multiphasic preparations can worsen mood symptoms (44). COC's containing drospirenone, especially with a $244+$ regimen [3 mg drospirenone (DRSP)/20 mcg ethinyl estradiol] with a shortened drug-free interval of four days are effective and approved by the Federal Drugs Agency for management of PMDD (71). In case of persistence of the PMS/PMDD symptoms and/or presence of intermediate bleeding that does not improve after three month of COC use, the dosage of ethinyl estradiol can be increased and a $21+7$ regimen with 3 mg DRSP/30 mcg ethinyl estradiol COC can be commenced. However, the 24/4 regimen is associated with better cycle control (72). The COC can be switched to an alternative formulation if drospirenone-containing $\mathrm{COC}$ fails to improve the symptoms or an SSRI can be added to COC monotherapy in order to improve the treatment results. Continuous use of $\mathrm{COC}$ is better than intermittent use. In two randomized studies $(73,74)$ and in a meta-analysis $(75)$, it was shown that COCs containing $20 \mathrm{mcg}$ ethinyl estradiol/3 mg drospirenone with a four-day confinement interval are more effective than placebo in reducing PMDD symptoms.

\section{Cognitive behavioral therapy}

CBT has been used previously in the treatment of depression and anxiety disorders in women, but data on its use for PMS/ PMDD are limited. While some studies report that it is useful $(76,77)$, others failed to show any statistically significant benefit (78). In a randomized study covering 174 women with PMDD, women in the internet-based cognitive behavioral intervention group experienced a decrease in symptom severity compared to a waiting list control group (76). The CBT course may be useful for some women, but data on this are limited and qualified health-service providers are required for delivering this treatment.

\section{Gonadotropin releasing hormone agonists}

In women with severe symptoms who cannot respond or tolerate SSRIs or COCs, the next step might be considering GnRH that provides a reversible medical oophorectomy (78). Although GnRH agonist therapy is effective in PMDD (79), it cannot be used for a long period due to the menopausal sideeffects related to estrogen deficiency, such as bone loss and genital atrophy. Depot leuprolide acetate $3.75 \mathrm{mg}$ per month is the first choice. Add-back therapy with $\mathrm{COC}$ is recommended if $\mathrm{GnRH}$ analog will be used longer than six months (44).

\section{Alternative hormonal therapies}

Percutaneous estradiol (100 mcg estradiol patches twice weekly) opposed with a cyclical 10-12 day course of oral or vaginal micronized progesterone or long-term progestogen with the LNG-IUS $52 \mathrm{~m}$ are recommended regimens for PMS (44). However, careful monitoring is required. Danazol $200 \mathrm{mg}$ twice daily is also effective in reducing the symptoms, although virilizing side-effects including weight gain, acne, hirsutism and deepening of the voice limits its use (44). Effective contraception must be provided during Danazol treatment as Danazol may cause virilization of the female fetus.

\section{Surgery}

As medical treatment of PMDD is usually successful, surgery [bilateral oophorectomy/bilateral salpingoophorectomy (surgical menopause)] is considered only in a very few patients who failed to respond to all the medical therapies described (44). Before surgery, all the pharmacological treatment modalities, especially administration of GnRH analogues, should be considered $(80,81)$. In young women HRT must be commenced after bilateral oophorectomy (44).

\section{Conclusion}

PMS and PMDD symptoms compromise the well-being of women and have a negative impact on quality of life. Definitive diagnosis is based on prospective self-reporting of the symptoms. Most cases are unrecognized as the presence of the symptoms is not usually questioned during gynecological exams and routine check-ups. Exercise, a healthy diet rich in vitamins and minerals and CBT are the first-line treatment modalities in mild cases. SSRIs and/or COCs are first-line pharmacologic treatments as they are effective in the majority of the women with PMS and PMDD symptoms. Alternative 
hormonal therapies can be utilized when the standard therapies fail. Surgery is the last resort and should not be considered until all the alternative medical treatment modalities have been tried and are ineffective.

\section{Peer-review: Externally peer-reviewed.}

\section{Conflict of Interest: No conflict of interest was declared by the} authors.

\section{Financial Disclosure: The authors declared that this study received no financial support.}

\section{References}

1. RCOG Green Top Guideline No 48. In: Panay N, ed. The management of premenstrual syndrome, www.rcog.org.uk; Dec 2007.

2. Wyatt K, Dimmock PW, O'Brien PM. Premenstrual syndrome. In: Barton S, ed. Clinical evidence. 4th issue. London: BMJ Publishing Group, 2000:1121-33.

3. Daugherty JE. Treatment strategies for premenstrual syndrome. Am Fam Physician 1998; 58: 183-92.

4. Moline ML, Zendell SM. Evaluating and managing premenstrual syndrome. Medscape Womens Health. 2000; 5: 1 .

5. Diagnostic and Statistical Manual of Mental Disorders (5th Edition). Arlington, VA: American Psychiatric Association. 2013. p. 625.4. Code: 625.4 (N94.3)

6. Wittchen HU, Becker E, Lieb R, Krause P. Prevalence, incidence and stability of premenstrual dysphoric disorder in the community. Psychol Med 2002; 32: 119-32.

7. Potter J, Bouyer J, Trussell J, Moreau C. Premenstrual syndrome prevalence and fluctuation over time: results from a French population-based survey. J Womens Health (Larchmt) 2009; 18: 319.

8. Borenstein J, Chiou CF, Dean B, Wong J, Wade S. Estimating direct and indirect costs of premenstrual syndrome. J Occup Environ Med 2005;47: 26-33.

9. Gehlert S, Song $\mathrm{IH}$, Chang $\mathrm{CH}$, Hartlage SA. The prevalence of premenstrual dysphoric disorder in a randomly selected group of urban and rural women. Psychol Med 2009; 39: 129-36.

10. Tschudin S, Bertea PC, Zemp E. Prevalence and predictors of premenstrual syndrome and premenstrual dysphoric disorder in a population-based sample. Arch Womens Ment Health 2010; 13: 485-94.

11. Direkvand-Moghadam A, Sayehmiri K, Delpisheh A, Kaikhavandi S. Epidemiology of premenstrual syndrome (PMS)-a systematic review and meta-analysis study. J Clin Diagn Res 2014; 8: 106-9.

12. Dennerstein L, Lehert P, Heinemann K. Global study of women's experiences of premenstrual symptoms and their effects on daily life. Menopause Int 2011; 17: 88-95.

13. Miller A, Vo H, Huo L, Roca C, Schmidt PJ, Rubinow DR. Estrogen receptor alpha (ESR-1) associations with psychological traits in women with PMDD and controls. J Psychiatr Res 2010; 44: 788-94.

14. Huo L, Straub RE, Roca C, Schmidt PJ, Shi K, Vakkalanka R, et al. Risk for premenstrual dysphoric disorder is associated with genetic variation in ESR1, the estrogen receptor alpha gene. Biol Psychiatry 2007; 62: 925-33.

15. Pakharenko L. Effect of estrogen receptor gene ESR1 polymorphism on development of premenstrual syndrome. Georgian Med News 2014; (235): 37-41.
16. Dubey N, Hoffman JF, Schuebel K, Yuan Q, Martinez PE, Nieman $\mathrm{LK}$, et al. The $\mathrm{ESC} / \mathrm{E}(\mathrm{Z})$ complex, an effector of response to ovarian steroids, manifests an intrinsic difference in cells from women with premenstrual dysphoric disorder. Mol Psychiatry 2017; 22: 1172-84.

17. Cohen LS, Soares CN, Otto MW, Sweeney BH, Liberman RF, Harlow BL. Prevalence and predictors of premenstrual dysphoric disorder (PMDD) in older premenopausal women. The Harvard Study of Moods and Cycles. J Affect Disord 2002; 70:125-32.

18. Perkonigg A, Yonkers KA, Pfister H, Lieb R, Wittchen HU. Risk factors for premenstrual dysphoric disorder in a community sample of young women: the role of traumatic events and posttraumatic stress disorder. J Clin Psychiatry 2004; 65: 1314-22.

19. Thys-Jacobs S, McMahon D, Bilezikian JP. Cyclical changes in calcium metabolism across the menstrual cycle in women with premenstrual dysphoric disorder. J Clin Endocrinol Metab 2007; 92: 2952-9.

20. Halbreich U, Rojansky N, Palter S. Elimination of ovulation and menstrual cyclicity (with danazol) improves dysphoric premenstrual syndromes. Fertil Steril 1991; 56: 1066-9.

21. Schmidt PJ, Nieman LK, Danaceau MA, Adams LF, Rubinow DR. Differential behavioral effects of gonadal steroids in women with and in those without premenstrual syndrome. N Engl J Med 1998 338: 209-16.

22. Schmidt PJ, Martinez PE, Nieman LK, Koziol DE, Thompson KD, Schenkel L, et al. Premenstrual Dysphoric Disorder Symptoms Following Ovarian Suppression: Triggered by Change in Ovarian Steroid Levels But Not Continuous Stable Levels. Am J Psychiatry 2017; 174: 980-9

23. Andersch B, Abrahamsson L, Wendestam C, Ohman R, Hahn L. Hormone profile in premenstrual tension: effects of bromocriptine and diuretics. Clin Endocrinol (Oxf) 1979; 11: 657-64.

24. Taylor JW. Plasma progesterone, oestradiol 17 beta and premenstrual symptoms. Acta Psychiatr Scand 1979; 60:76-86.

25. Schmidt PJ, Purdy RH, Moore PH Jr, Paul SM, Rubinow DR. Circulating levels of anxiolytic steroids in the luteal phase in women with premenstrual syndrome and in control subjects. J Clin Endocrinol Metab 1994; 79: 1256-60.

26. Chan AF, Mortola JF, Wood SH, Yen SS. Persistence of premenstrua syndrome during low-dose administration of the progesterone antagonist RU 486. Obstet Gynecol 1994; 84: 1001-5.

27. Wardlaw SL, Thoron L, Frantz AG. Effects of sex steroids on brain beta-endorphin. Brain Res 1982; 245: 327-31.

28. Majewska MD, Harrison NL, Schwartz RD, Barker JL, Paul SM. Steroid hormone metabolites are barbiturate-like modulators of the GABA receptor. Science 1986; 232:1004-7.

29. Bethea CL. Regulation of progestin receptors in raphe neurons of steroid-treated monkeys. Neuroendocrinology 1994; 60: 50-61.

30. Smith S, Rinehart JS, Ruddock VE, Schiff I. Treatment of premenstrual syndrome with alprazolam: results of a double-blind, placebo-controlled, randomized crossover clinical trial. Obstet Gynecol 1987; 70: 37-43.

31. Rapkin AJ, Morgan M, Goldman L, Brann DW, Simone D, Mahesh VB. Progesterone metabolite allopregnanolone in women with premenstrual syndrome. Obstet Gynecol 1997; 90: 709-14.

32. Rapkin AJ, Edelmuth E, Chang LC, Reading AE, McGuire MT, Su TP. Whole-blood serotonin in premenstrual syndrome. Obstet Gynecol 1987; 70: 533-7.

33. Taylor DL, Mathew RJ, Ho BT, Weinman ML. Serotonin levels and platelet uptake during premenstrual tension. Neuropsychobiology 1984; 12: 16-8.

34. Ashby CR Jr, Carr LA, Cook CL, Steptoe MM, Franks DD. Alteration of platelet serotonergic mechanisms and monoamine oxidase activity in premenstrual syndrome. Biol Psychiatry 1988; 24: 225-33. 
35. Steege JF, Stout AL, Knight DL, Nemeroff CB. Reduced platelet tritium-labeled imipramine binding sites in women with premenstrual syndrome. Am J Obstet Gynecol 1992; 167: 168-72.

36. Rojansky N, Halbreich U, Zander K, Barkai A, Goldstein S. Imipramine receptor binding and serotonin uptake in platelets of women with premenstrual changes. Gynecol Obstet Invest 1991; 31: 146-52.

37. Eriksson E, Alling C, Andersch B, Andersson K, Berggren U. Cerebrospinal fluid levels of monoamine metabolites. A preliminary study of their relation to menstrual cycle phase, sex steroids, and pituitary hormones in healthy women and in women with premenstrual syndrome. Neuropsychopharmacology 1994; 11: 201-13.

38. Brzezinski AA, Wurtman JJ, Wurtman RJ, Gleason R, Greenfield J, Nader T. d-Fenfluramine suppresses the increased calorie and carbohydrate intakes and improves the mood of women with premenstrual depression. Obstet Gynecol 1990; 76: 296-301.

39. Menkes DB, Coates DC, Fawcett JP. Acute tryptophan depletion aggravates premenstrual syndrome. J Affect Disord 1994; 32: 37-44.

40. Chuong CJ, Dawson EB, Smith ER. Vitamin A levels in premenstrual syndrome. Fertil Steril 1990; 54: 643-7.

41. Chuong CJ, Dawson EB, Smith ER. Vitamin E levels in premenstrual syndrome. Am J Obstet Gynecol 1990; 163: 1591-5.

42. Chocano-Bedoya PO, Manson JE, Hankinson SE, Johnson SR, Chasan-Taber L, Ronnenberg AG, et al. Intake of selected minerals and risk of premenstrual syndrome. Am J Epidemiol. 2013; 177: 1118-27.

43. ACOG Practice Bulletin: Premenstrual Syndrome. Int J Gynecol Obstet 2001; 73: 183-91.

44. Green LJ, O'Brien PMS, Panay N, Craig M on behalf of the Royal College of Obstetricians and Gynaecologists. Management of premenstrual syndrome. BJOG 2017; 124: e73-105.

45. O'Brien PM, Bäckström T, Brown C, Dennerstein L, Endicott J, Epperson $\mathrm{CN}$, et al. Towards a consensus on diagnostic criteria, measurement and trial design of the premenstrual disorders: the ISPMD Montreal consensus. Arch Womens Ment Health 2011; 14: $13-21$.

46. Nevatte T, O'Brien PM, Bäckström T, Brown C, Dennerstein L, Endicott $\mathrm{J}$, et al; Consensus Group of the International Society for Premenstrual Disorders. ISPMD consensus on the management of premenstrual disorders. Arch Womens Ment Health 2013; 16: 279-91.

47. Mortola JF, Girton L, Beck L, Yen SS. Diagnosis of premenstrual syndrome by a simple, prospective, and reliable instrument: the calendar of premenstrual experiences. Obstet Gynecol 1990; 76: 302-7.

48. Yonkers KA, O'Brien PM, Eriksson E. Premenstrual syndrome. Lancet 2008; 371: 1200-10.

49. Hartlage SA, Freels S, Gotman N, Yonkers K. Criteria for premenstrual dysphoric disorder: secondary analyses of relevant data sets. Arch Gen Psychiatry 2012; 69: 300-5.

50. Casper RF, Graves GR, Reid RL. Objective measurement of hot flushes associated with the premenstrual syndrome. Fertil Steril 1987; 47: 341-4.

51. Dean BB, Borenstein JE, Knight K, Yonkers K. Evaluating the criteria used for identification of PMS. J Womens Health (Larchmt) 2006; 15: 546-55.

52. Borenstein JE, Dean BB, Leifke E, Korner P, Yonkers KA. Differences in symptom scores and health outcomes in premenstrual syndrome. J Womens Health (Larchmt) 2007; 16: 1139-44.

53. Mohebbi Dehnavi Z, Jafarnejad F, Sadeghi Goghary S. The effect of 8 weeks aerobic exercise on severity of physical symptoms of premenstrual syndrome: a clinical trial study. BMC Womens Health 2018; 18: 80 .
54. van Die MD, Burger HG, Teede HJ, Bone KM. Vitex agnus-castus extracts for female reproductive disorders: a systematic review of clinical trials. Planta Med 2013; 79: 562-75.

55. Stewart A. Vitamin B6 in the treatment of the premenstrual syndrome--review. Br J Obstet Gynaecol 1991; 98: 329-30.

56. Shah NR, Jones JB, Aperi J, Shemtov R, Karne A, Borenstein J. Selective serotonin reuptake inhibitors for premenstrual syndrome and premenstrual dysphoric disorder: a meta-analysis. Obstet Gynecol 2008; 111: 1175-82.

57. Marjoribanks J, Brown J, O'Brien PM, Wyatt K. Selective serotonin reuptake inhibitors for premenstrual syndrome. Cochrane Database Syst Rev 2013; 2013: CD001396.

58. Stone AB, Pearlstein TB, Brown WA. Fluoxetine in the treatment of premenstrual syndrome. Psychopharmacol Bull 1990; 26: 331-5.

59. Freeman EW, Rickels K, Yonkers KA, Kunz NR, McPherson M, Upton GV. Venlafaxine in the treatment of premenstrual dysphoric disorder. Obstet Gynecol 2001; 98: 737-44.

60. Cohen LS, Soares CN, Lyster A, Cassano P, Brandes M, Leblanc GA. Efficacy and tolerability of premenstrual use of venlafaxine (flexible dose) in the treatment of premenstrual dysphoric disorder. J Clin Psychopharmacol 2004; 24: 540-3.

61. Sundblad C, Modigh K, Andersch B, Eriksson E. Clomipramine effectively reduces premenstrual irritability and dysphoria: a placebo-controlled trial. Acta Psychiatr Scand 1992; 85: 39-47.

62. Sundblad C, Hedberg MA, Eriksson E. Clomipramine administered during the luteal phase reduces the symptoms of premenstrual syndrome: a placebo-controlled trial. Neuropsychopharmacology 1993; 9: 133-45.

63. Freeman EW, Rickels K, Sondheimer SJ, Polansky M. Differential response to antidepressants in women with premenstrual syndrome/premenstrual dysphoric disorder: a randomized controlled trial. Arch Gen Psychiatry 1999; 56: 932-9.

64. Treatment of premenstrual syndrome and premenstrual dysphoric disorder-Up To Date Literature review current through: Jun 2020. | This topic last updated: Nov 26, 2019

65. Cohen LS, Miner C, Brown EW, Freeman E, Halbreich U, Sundell $\mathrm{K}$, et al. Premenstrual daily fluoxetine for premenstrual dysphoric disorder: a placebo-controlled, clinical trial using computerized diaries. Obstet Gynecol 2002; 100: 435-44.

66. Miner C, Brown E, McCray S, Gonzales J, Wohlreich M. Weekly luteal-phase dosing with enteric-coated fluoxetine $90 \mathrm{mg}$ in premenstrual dysphoric disorder: a randomized, double-blind, placebo-controlled clinical trial. Clin Ther 2002; 24:417-33.

67. Yonkers KA, Holthausen GA, Poschman K, Howell HB. Symptomonset treatment for women with premenstrual dysphoric disorder. J Clin Psychopharmacol 2006; 26: 198-202.

68. Yonkers KA, Kornstein SG, Gueorguieva R, Merry B, Van Steenburgh $\mathrm{K}$, Altemus M. Symptom-Onset Dosing of Sertraline for the Treatment of Premenstrual Dysphoric Disorder: A Randomized Clinical Trial. JAMA Psychiatry 2015; 72: 1037-44.

69. Wikander I, Sundblad C, Andersch B, Dagnell I, Zylberstein D, Bengtsson F, et al. Citalopram in premenstrual dysphoria: is intermittent treatment during luteal phases more effective than continuous medication throughout the menstrual cycle? J Clin Psychopharmacol 1998; 18: 390-8.

70. Akdağ Cirik D, Dilbaz B, Aksakal S, Kotan Z, Özelçi R, Akpınar F, et al. Do anxiety and depression statuses differ in differentpolycystic ovary syndrome phenotypes? Turk J Med Sci 2016; 46: 1846-53.

71. Pearlstein TB, Bachmann GA, Zacur HA, Yonkers KA. Treatment of premenstrual dysphoric disorder with a new drospirenonecontaining oral contraceptive formulation. Contraception 2005; 72: $414-21$. 
72. Tekeli A, Dilbaz B, Kiykac Altinbas S, Bayoğlu Tekin Y. Comparison of short-term efficacy, side effects, benefits of two drospirenone containing combined oral contraceptives: $21 / 7$-day-3mg/30mcg vs. 24/4-day-3mg/20 mcg. Fertil Steril 2012; 98(Suppl 3): S193.

73. Skovlund CW, Mørch LS, Kessing LV, Lidegaard Ø. Association of hormonal contraception with depression. JAMA Psychiatry 2016; 73: 1154-62.

74. Yonkers KA, Brown C, Pearlstein TB, Foegh M, Sampson-Landers C, Rapkin A. Efficacy of a new low-dose oral contraceptive with drospirenone in premenstrual dysphoric disorder. Obstet Gynecol 2005; 106: 492-501.

75. Lopez LM, Kaptein AA, Helmerhorst FM. Oral contraceptives containing drospirenone for premenstrual syndrome. Cochrane Database Syst Rev 2009:CD006586.

76. Weise C, Kaiser G, Janda C, Kues JN, Andersson G, Strahler J, et al. Internet-Based Cognitive-Behavioural Intervention for Women with Premenstrual Dysphoric Disorder: A Randomized Controlled Trial. Psychother Psychosom 2019; 88: 16-29.
77. Evaluation of the relative efficacy of a couple cognitive-behaviour therapy (CBT) for Premenstrual Disorders (PMDs), in comparison to one-to-one CBT and a wait list control: A randomized controlled trial. PLoS One 2017; 12: e0175068.

78. Lustyk MK, Gerrish WG, Shaver S, Keys SL. Cognitive-behavioral therapy for premenstrual syndrome and premenstrual dysphoric disorder: a systematic review. Arch Womens Ment Health 2009; 12 : 85-96.

79. Brown CS, Ling FW, Andersen RN, Farmer RG, Arheart KL. Efficacy of depot leuprolide in premenstrual syndrome: effect of symptom severity and type in a controlled trial. Obstet Gynecol 1994; 84: 77986.

80. Cronje WH, Vashisht A, Studd JW. Hysterectomy and bilateral oophorectomy for severe premenstrual syndrome. Hum Reprod 2004; 19: 2152-5.

81. Posaci C, Erten O, Uren A, Acar B. Plasma copper, zinc and magnesium levels in patients with premenstrual tension syndrome. Acta Obstet Gynecol Scand 1994; 73: 452-5. 